\title{
Persistent Left Superior Vena Cava Identified After Hemodialysis Catheter Insertion: A Case Report
}

This article was published in the following Dove Press journal: International Medical Case Reports Journal

\author{
Metalia Puspitasari $\mathbb{D}^{\prime}$ \\ Hemi Sinorita ${ }^{2}$ \\ Hendry Purnasidha Bagaswoto ${ }^{3}$ \\ Iri Kuswadi' \\ Heru Prasanto' \\ Yulia Wardhani' \\ Wahyu Tri Kurniawan (D) \\ 'Division of Nephrology and \\ Hypertension, Department of Internal \\ Medicine, Faculty of Medicine, Universitas \\ Gadjah Mada - Dr. Sardjito Hospital, \\ Yogyakarta, Indonesia; ${ }^{2}$ Division of \\ Endocrinology, Department of Internal \\ Medicine, Faculty of Medicine, Universitas \\ Gadjah Mada - Dr. Sardjito Hospital, \\ Yogyakarta, Indonesia; ${ }^{3}$ Department of \\ Cardiology and Vascular Medicine, \\ Faculty of Medicine, Universitas Gadjah \\ Mada - Dr. Sardjito Hospital, Yogyakarta, \\ Indonesia
}

Introduction: Central venous catheter (CVC) insertion is the most commonly performed clinical procedure when a patient initiates hemodialysis. Despite its clinical benefits, CVC insertion has several risks of complications. Thrombosis, venous stenosis, infection, arrhythmia, pneumothorax, and bleeding are among these complications. Malposition of the tip of the CVC can also occur with an incidence of up to $7 \%$. One of several factors that could contribute to malposition is venous anatomy variation. Persistent left superior vena cava (PLSVC) is an extremely rare venous anatomical disorder but might have a significant clinical impact.

Case Presentation: Here we report a PLSVC case that was identified in chest radiography after the insertion of a CVC catheter in a patient with end-stage renal disease (ESRD). A 40year-old woman with a history of type 2 diabetes mellitus, hypertension, dyslipidemia, and obesity was presented in the emergency room with dyspnea for 1 week. Acute hemodialysis was required because of the ESRD and pulmonary edema. The PLSVC condition accompanied by various complications that occurred in this patient became a dilemma for the nephrologist in determining the diagnosis and proper CVC management.

Discussion: PLSVC is the most common congenital abnormality of the vena cava, even though it has a very small incidence. PLSVC occurs in about $0.1-0.5 \%$ of the total population and reaches $10 \%$ in individuals with congenital heart abnormalities. Most PLSVC presents along with normal superior vena cava and drains into the right atrium, which makes it very difficult to see the clinical signs and symptoms. Almost all PLSVC conditions are found incidentally during or after invasive procedures such as CVC insertion. CVC insertion in the PLSVC condition needs proper management to minimize the risk of complications.

Conclusion: This case shows the importance of understanding the PLSVC condition, which, although very rare, is expected to increase the awareness of the nephrologist in making the diagnosis, determining appropriate management, and preventing complications, thereby improving patient safety.

Keywords: persistent left superior vena cava, PLSVC, central venous catheter, CVC, malposition, hemodialysis, end-stage renal disease, ESRD

\section{Introduction}

Central venous catheter (CVC) insertion is the most commonly performed clinical procedure when a patient initiates hemodialysis. ${ }^{1}$ Although the National Kidney Foundation recommends using AV access (fistula or graft) for hemodialysis initiation, the use of CVC still dominates with an incidence reaching $80 \% .{ }^{1,2}$ Its ability to
Division of Nephrology and Hypertension, Department of Internal Medicine, Faculty of Medicine, Universitas Gadjah Mada -

Dr. Sardjito Hospital, Jl. Kesehatan No. I, Yogyakarta 55284, Indonesia

$\mathrm{Tel}+628116110283$

Email puspitasarimetalia@gmail.com
International Medical Case Reports Journal 2020:13 465-469 
be used immediately after insertion makes it preferred for use in urgent or emergent conditions. ${ }^{3}$

Despite its clinical benefits, CVC insertion has several risks of complications. Thrombosis, venous stenosis, infection, arrhythmia, pneumothorax, and bleeding are among these complications. ${ }^{4,5}$ Malposition of the tip of the CVC can also occur with an incidence of up to $7 \%{ }^{6}$ Several factors could contribute to malposition, such as bevel orientation upon needle insertion, the patient's body habitus, and venous anatomy variation. ${ }^{6}$ Persistent left superior vena cava (PLSVC) is an extremely rare venous anatomical disorder but might have a significant clinical impact. ${ }^{7}$

Here we report a PLSVC case that was identified in chest radiography after the insertion of a CVC catheter in a patient with end-stage renal disease (ESRD).

\section{Case Presentation}

A 40-year-old woman with a history of type 2 diabetes mellitus, hypertension, dyslipidemia, and obesity, presented in the emergency room with dyspnea for 1 week. Patient was hospitalized with the diagnosis of communityacquired pneumonia (CAP) and diabetic foot ulcer with secondary sepsis. Acute hemodialysis was required because of the ESRD and pulmonary edema.

The first CVC for hemodialysis was immediately inserted to the right subclavian venous using ultrasound guidance. In the chest X-ray evaluation, the tip of the catheter appeared to be at the projection of superior vena cava and right atrium border. After 1 week of usage, the catheter was immediately removed due to thrombus and bloodstream infection.

The second CVC insertion was delayed until the 13th day of hospitalization due to the patient's unstable hemodynamics. The catheter was inserted using ultrasound guidance through the left jugular vein because of thrombus in the right side. There were no signs of hypotension, cyanosis, or bleeding during and after the insertion. The electrocardiography showed normal sinus rhythm. In the post-insertion chest $x$-ray evaluation, the tip of the catheter appeared to be at the left mediastinum (Figure 1).

The left internal jugular or subclavian catheter insertion should cross the midline to reach the right atrium. The inadvertent cannulation of the carotid artery was ruled out by blood gas analysis. An echocardiography was performed in the following day to confirm whether there was PLSVC. The result showed that there was definitely PLSVC (Figure 2).

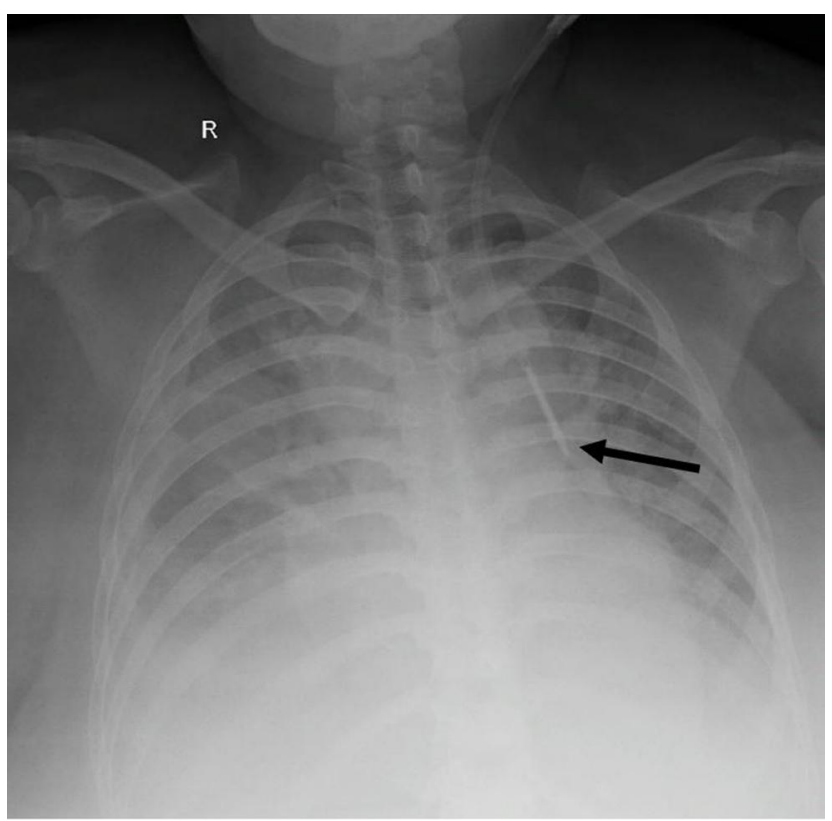

Figure I Anteroposterior chest x-ray shows the tip of the catheter inserted through the left jugular vein was located in the left mediastinum (black arrow).

The patient's condition worsened despite the optimal treatment. She died on the 16th day of hospitalization due to septic and hemorrhagic shock. The use of PLSVC as hemodialysis access could not be evaluated because the hemodialysis procedure was not done.

\section{Discussion}

PLSVC is the most common congenital abnormality of the vena cava, even though it has a very small incidence. PLSVC occurs in about $0.1-0.5 \%$ of the total population and reaches $10 \%$ in individuals with congenital heart abnormalities. $^{7}$ The abnormalities that are most commonly found together with PLSVC are atrial septal defect, ventricular septal defect, and aortic coarctation. ${ }^{5}$ In clinical practice, venous system imaging is not routinely performed on patients who will undergo invasive procedures such as CVC insertion, so it is almost certain PLSVC will be found incidentally during or after the procedure. ${ }^{8}$

In normal embryological development, the venous system consists of two pairs of cardinal veins symmetrically located. The cranial portions of both anterior cardinal veins form the internal jugular veins. The caudal portion of the right anterior cardinal vein develops into the superior vena cava while the left regresses into the ligament of Marshall. The failure of this regression will cause PLSVC (Figure 3).., 10 

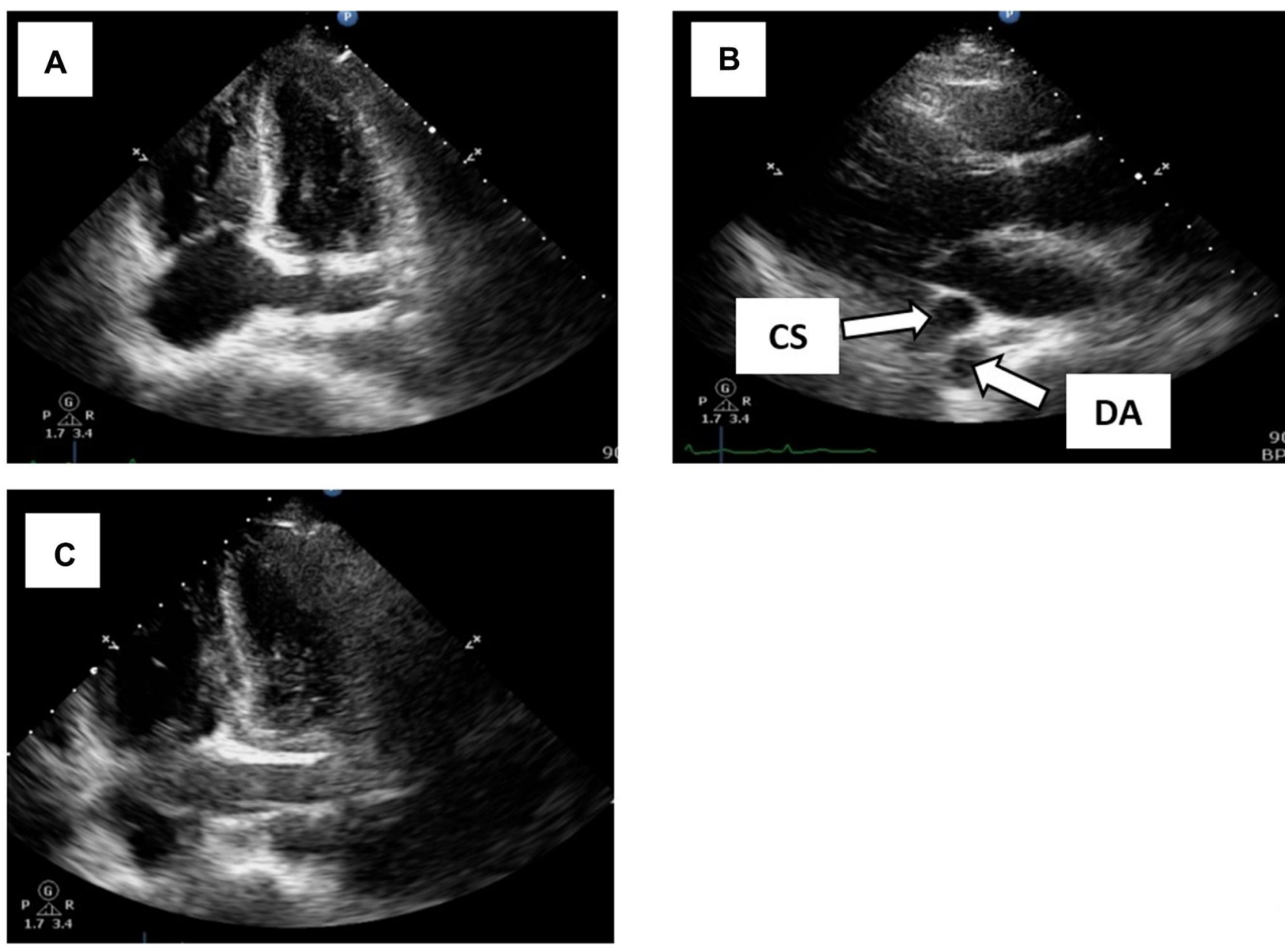

Figure 2 Echocardiography examination shows: (A) Coronary sinus enlargement due to the blood flow from PLSVC to right atrium (RA); (B) PLAX view shows that there is an enlargement of the coronary sinus (CS) adjacent to the descendant aorta (DA); and (C) Bubble test injected through the left cubital vein shows air bubbles filling the right atrium through the coronary sinus.

There are four types of superior vena cava based on Schummer's classification (Table 1) ${ }^{11}$ About $80 \%$ of the PLSVC present along with the normal superior vena cava and most of the PLSVC (92\%) drains into the right atrium. Both of these make most PLSVC cases asymptomatic. ${ }^{9,12}$

Based on a guideline for determining the location of catheter malposition by Gibson and Bodenham, ${ }^{13}$ the position of the hemodialysis catheter in this patient was consistent with the PLSVC condition. The criteria are that blood flow can pass through all lumens, with venous blood characteristics (low flow, non-pulsatile, dark color), and is located in the left mediastinum when evaluated by chest $\mathrm{x}$-ray. Echocardiography can be used to diagnose PLSVC quickly and non-invasively, ${ }^{14}$ as was done in this patient. Despite its small proportion (8\%), PLSVC which drains into the left atrium can cause serious complications, such as embolization. ${ }^{12}$ Additional diagnostic studies can be used to detect the presence and ascertain the drainage of PLSVC, such as radionuclide angiocardiography, computerized tomography (CT) scan, or magnetic resonance venography. ${ }^{9}$

Some nephrologists believed that PLSVC has relatively thin walls and low blood flow, making it unsuitable for long-term access to hemodialysis. ${ }^{7}$ Use of PLSVC as hemodialysis access was also associated with some complications, including arrhythmia, pericardial effusion, thrombus formation, and reduced blood flow to the heart. ${ }^{7,15-17}$ However, literature reviews of the same case show the possibility of PLSVC being used as hemodialysis access in short- and long-term hemodialysis patients, certainly with tighter monitoring. ${ }^{7,14}$

Management of CVC malposition must be based on several considerations: the indication of insertion, the location of insertion, and the condition of the patient. ${ }^{13}$ If there are difficulties as in this case, the risks and benefits of the inserted CVC must be considered. ${ }^{6}$ The patient in this case 


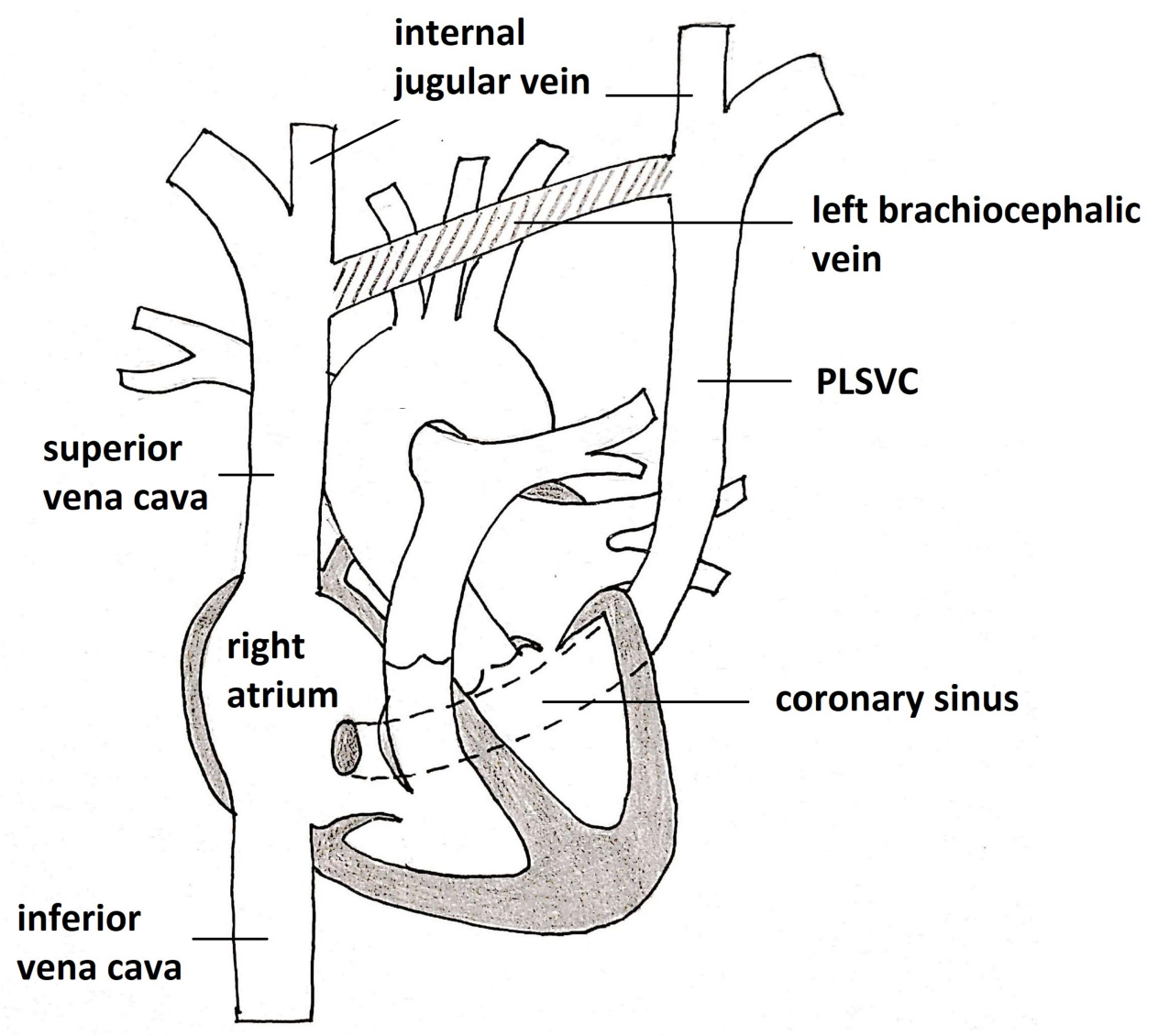

Figure 3 Schematic illustration of persistent left superior vena cava. Redrawn with data from these studies. ${ }^{7,11,19}$

was critically ill, so immediate removal of the catheter was considered to worsen the condition. Removal of the catheter in conditions that are not optimal can increase the risk of complications, morbidity and mortality. ${ }^{18}$

\section{Conclusions}

PLSVC is a very rare congenital vena cava disorder, mostly with no symptoms, and is generally found incidentally during invasive procedures such as hemodialysis catheter insertion. The location of the tip of the catheter that is attached via PLSVC can be confirmed when it drains into the right atrium, does not provide complications and then can be used for

Table I Classification of Superior Vena Cava

\begin{tabular}{|l|l|}
\hline Types & Description \\
\hline I & $\begin{array}{l}\text { Normal (right) superior vena cava present, PLSVC absent } \\
\text { Right superior vena cava absent, PLSVC present } \\
\text { IIla }\end{array}$ \\
IIlb & $\begin{array}{l}\text { Both superior vena cava present with left brachiocephalic } \\
\text { vein in between } \\
\text { brachiocephalic vein in between }\end{array}$ \\
\hline
\end{tabular}

short-term hemodialysis with tighter monitoring. By understanding this condition, a nephrologist is expected to be more aware, can make the diagnosis, determining appropriate management, and preventing complications, thereby improving patient safety.

\section{Statement of Ethics}

This study was conducted ethically in accordance with the World Medical Association Declaration of Helsinki. The information used did not identify any individual, and the subject's identity was kept confidential. A written informed consent was obtained from the patient's family for publication of this manuscript. Institutional approval was not required to publish the case details.

\section{Disclosure}

The authors report no conflicts of interest in this work.

\section{References}

1. Moist LM, Lok CE. Incident dialysis access in patients with end-stage kidney disease: what needs to be improved. Semin Nephrol. 2017;37 (2):151-158. doi:10.1016/j.semnephrol.2016.12.005 
2. Lok CE, Huber TS, Lee T, et al. KDOQI clinical practice guideline for vascular access: 2019 update. Am J Kidney Dis. 2020;75(4):S1164. doi:10.1053/j.ajkd.2019.12.001

3. Haddad NJ, Cleef SV, Agarwal AK. Central venous catheters in dialysis: the good, the bad and the ugly. Open Urol Nephrol J. 2012;5(1):12-18. doi:10.2174/1874303X01205010012

4. Nayeemuddin M, Pherwani AD, Asquith JR. Imaging and management of complications of central venous catheters. Clin Radiol. 2013;68(5):529-544. doi:10.1016/j.crad.2012.10.013

5. Povoski SP, Khabiri H. Persistent left superior vena cava: review of the literature, clinical implications, and relevance of alterations in thoracic central venous anatomy as pertaining to the general principles of central venous access device placement and venography in cancer patients. World J Surg Oncol. 2011;9:173.

6. Roldan CJ, Paniagua L. Central venous catheter intravascular malpositioning: causes, prevention, diagnosis, and correction. West J Emerg Med. 2015;16(5):658-664. doi:10.5811/westjem.2015.7.26248

7. He H, Li B, Ma Y, et al. Catheterization in a patient with end-stage renal disease through persistent left superior vena cava: a rare case report and literature review. BMC Nephrol. 2019;20(1):202. doi:10.1186/s12882-019-1339-5

8. Sahutoglu T, Sakaci T, Kara E, et al. Persistent left superior vena cava: two case reports and a review from nephrologists' perspective. Hemodial Int. 2016;20(3):369-377. doi:10.1111/hdi.12389

9. Granata A, Andrulli S, Fiorini F, et al. Persistent left superior vena cava: what the interventional nephrologist needs to know. $J$ Vasc Access. 2009;10(3):207-211. doi:10.1177/112972980901000313

10. Ratliff HL, Yousufuddin M, Lieving WR, et al. Persistent left superior vena cava: case reports and clinical implications. Int $J$ Cardiol. 2006;113(2):242-246. doi:10.1016/j.ijcard.2005.08.067

11. Schummer W, Schummer C, Fröber R. Persistent left superior vena cava and central venous catheter position: clinical impact illustrated by four cases. Surg Radiol Anat. 2003;25(3-4):315-321. doi:10.1007/ s00276-003-0138-6
12. Zhou Q, Murthy S, Pattison A, et al. Central venous access through a persistent left superior vena cava: a case series. J Vasc Access. 2016;17(5):e143-e147. doi:10.5301/jva.5000554

13. Gibson F, Bodenham A. Misplaced central venous catheters: applied anatomy and practical management. Br $J$ Anaesth. 2013;110 (3):333-346. doi:10.1093/bja/aes497

14. Kute VB, Vanikar AV, Gumber MR, et al. Hemodialysis through persistent left superior vena cava. Indian J Crit Care Med. 2011;15 (1):40-42. doi:10.4103/0972-5229.78223

15. Dionisio P, Borsetti C, Valenti M, et al. Knowledge of the anomalies of the big central veins reduces the morbidity during the cannulation for hemodialysis: description of a case of persistent left superior vena cava and revision of literature. J Vasc Access. 2003;4(1):25-31. doi:10.5301/jva.2008.3680

16. Balasubramanian S, Gupta S, Nicholls M, et al. Rare complication of a dialysis catheter insertion. Clin Kidney J. 2014;7(2):194-196. doi:10.1093/ckj/sfu006

17. Kawasaki T, Tanaka H, Oba M, Takada M, Tanaka H, Suda S. Persistent left superior vena cava with thrombus formed in the catheter lumen $4 \mathrm{~h}$ after dialysis catheter placed. CEN Case Rep. 2018;7 (1):158-161. doi:10.1007/s13730-018-0317-2

18. Bernard LA, Katzman A, Mathew DK, et al. Prevention of central venous catheter removal-associated air embolization. Am $\mathrm{J} \mathrm{Med}$. 2018;131(3):e123. doi:10.1016/j.amjmed.2017.10.023

19. Bisoyi S, Dash A, et al. Isolated persistent left superior vena cava: A case report and its clinical implications. Ann Card Anaesth. 2017;20 (1):104-107.

\section{Publish your work in this journal}

The International Medical Case Reports Journal is an international, peer-reviewed open-access journal publishing original case reports from all medical specialties. Previously unpublished medical posters are also accepted relating to any area of clinical or preclinical science. Submissions should not normally exceed 2,000 words or 4 published pages including figures, diagrams and references. The manuscript management system is completely online and includes a very quick and fair peer-review system, which is all easy to use. Visit http://www.dovepress.com/testimonials.php to read real quotes from published authors. 